\title{
ARTICLE OPEN Application of a novel socioeconomic measure using individual housing data in asthma research: an exploratory study
}

\author{
Malinda N Harris ${ }^{1}$, Matthew C Lundien², Dawn M Finnie ${ }^{3}$, Arthur R Williams ${ }^{4}$, Timothy J Beebe ${ }^{3}$, Jeffrey A Sloan ${ }^{3}$,
} Barbara P Yawn ${ }^{5}$ and Young J Juhn ${ }^{1,3,6}$

BACKGROUND: A housing-based socioeconomic index (HOUSES) was previously developed to overcome an absence of socioeconomic status (SES) measures in common databases. HOUSES is associated with child health outcomes in Olmsted County, Minnesota, USA, but generalisability to other geographic areas is unclear.

AIM: To assess whether HOUSES is associated with asthma outcomes outside Olmsted County, Minnesota, USA.

METHODS: Using a random sample of children with asthma from Sanford Children's Hospital, Sioux Falls, SD, USA, asthma status was determined. The primary outcome was asthma control status using Asthma Control Test and a secondary outcome was risk of persistent asthma. Home address information and property data were merged to formulate HOUSES. Other SES measures were examined: income, parental education (PE), Hollingshead and Nakao-Treas index.

RESULTS: Of a random sample of 200 children, 80 (40\%) participated in the study. Of those, $13 \%$ had poorly controlled asthma. Addresses of $94 \%$ were matched with property data. HOUSES had moderate-good correlation with other SES measures except PE. Poor asthma control rates were $31.6 \%, 4.8 \%$ and $5.6 \%$ for patients in the lowest, intermediate and highest tertiles of HOUSES, respectively $(P=0.023)$. HOUSES as a continuous variable was inversely associated with poorly controlled asthma (adjusted odds ratio $(\mathrm{OR})=0.21$ per 1 unit increase of HOUSES, 95\% confidence interval $(\mathrm{Cl}), 0.05-0.89, P=0.035)$. HOUSES as a continuous variable was inversely related to risk of persistent asthma (OR: 0.36 per 1 unit increase of HOUSES, 95\% $\mathrm{Cl}, 0.12-1.04, P=0.06$ ).

CONCLUSIONS: HOUSES appears to be generalisable and available as a measure of SES in asthma research in the absence of conventional SES measures.

npj Primary Care Respiratory Medicine (2014) 24, 14018; doi:10.1038/npjpcrm.2014.18; published online 26 June 2014

\section{INTRODUCTION}

Socioeconomic status (SES) is associated with various health outcomes including asthma in adults and children., ${ }^{1,2}$ There are significant disparities in asthma control status among children with different SES, with those from lower SES having poorer asthma control compared with children from higher SES. ${ }^{3,4}$ Despite the influence of SES on health outcomes, common measures of SES are difficult to obtain in routinely used data sources for clinical research such as administrative data sets and medical records. ${ }^{5-7}$ SES measures at an aggregate level (e.g., census tract, block-group or zip code) are used as proxy measures for individual SES. ${ }^{8,9}$ However, our recent study showed that area-level SES misclassified individual-level SES measures in a significant proportion of subjects $(22-31 \%){ }^{10}$ These results suggest that routine use of area-level measures of SES as a proxy measure of individual SES measure can be misleading.

As an alternative to the area-level SES measures, we previously developed and validated a housing-based measure of SES termed HOUSES by conducting a cross-sectional study in Olmsted County, Minnesota, and Jackson County, Missouri: the higher the HOUSES index, the higher the SES. ${ }^{11-13}$ The index was created by linking address information to publicly available property data available at local government assessors' office in the patients' place of residence.
The HOUSES index has been associated with health outcomes among children such as risk of overweight, low birth weight, exposure to cigarette smoking at home, general health status and invasive pneumococcal disease. ${ }^{11-13}$ Yet, little is known about whether HOUSES can be applied to a study setting outside of Olmsted or Jackson counties and whether HOUSES is associated with asthma outcomes.

Thus, we conducted an exploratory cross-sectional study to determine whether HOUSES is associated with asthma control status among asthmatic children. We hypothesised that HOUSES would be an easily accessible measure of individual-level SES outside of Olmsted County and would be associated with asthma control status, the primary study outcome.

\section{MATERIALS AND METHODS}

This study was reviewed and approved by the Mayo Clinic and Sanford Children's Hospital Institutional Review Boards.

\section{Study design and population}

The study was designed as a cross-sectional study, identifying a random sample of children from all eligible asthmatic children enrolled in Sanford Children's Hospital. Parents who agreed to participate completed a survey questionnaire utilised in our original study for the development and validation of HOUSES (derived from the 2002 National Health Interview

\footnotetext{
${ }^{1}$ Department of Pediatric and Adolescent Medicine, Mayo Clinic, Rochester, MN, USA; ${ }^{2}$ Mercy Clinic, Springfield, MO, USA; ${ }^{3}$ Department of Health Science Research, Mayo Clinic, Rochester, MN, USA; ${ }^{4}$ CIDRR8, James A. Haley VA Hospital, Tampa, FL, USA; ${ }^{5}$ Olmsted Medical Center, Mayo Clinic, Rochester, MN, USA and ${ }^{6}$ Department of Internal Medicine, Mayo Clinic, Rochester, MN, USA.

Correspondence: YJ Juhn (juhn.young@mayo.edu)

Received 19 November 2013; revised 19 March 2014; accepted 25 March 2014
} 
Survey). ${ }^{14}$ This survey questionnaire was to be returned by mail. Also, we conducted a comprehensive medical record review to determine asthma status and collect pertinent variables.

\section{Study subjects}

As a sampling frame, we used an administrative registry of children with asthma enrolled at Sanford Children's Hospital who were evaluated by pulmonologists and who met criteria for asthma. Study subjects were a random sample of 200 eligible children with asthma aged 4-18 years from the sampling frame. Subject recruitment is summarised in the flow diagram depicted in Figure 1. The eligibility criteria included children (1) who were diagnosed with asthma by a paediatric pulmonologist; (2) who were enrolled at Sanford Children's Hospital in Sioux Falls, South Dakota; (3) who resided in Sioux Falls (Minnehaha and Lincoln Counties), South Dakota, at the time of enrolment in 2007; and (4) who provided research authorisation to access medical records for research.

Response (dependent) variables

Asthma status was determined by predetermined criteria for asthma that are delineated in Box $1 .{ }^{15}$ These criteria have been extensively used for asthma research and were found to have high reliability. ${ }^{16,17}$ The primary response variable of interest was asthma control status determined by Asthma Control Test (ACT). ${ }^{18}$ A secondary outcome measure included asthma severity as determined by the 2007 National Asthma Education and Prevention Program, Expert Panel Report (NAEPP, EPR3) guidelines. ${ }^{19}$

Asthma control status as the primary study outcome. Asthma control status was treated as a categorical variable with $\leqslant 19$ (range of $5-25$ for children $\geqslant 12$ years or older or $0-27$ for children $4-11$ years) considered inadequately controlled asthma. ${ }^{20-22}$

Asthma severity as a secondary outcome. Asthma severity was determined by application of the 2007 NAEPP guidelines and categorised into two groups (inactive or mild-intermittent versus persistent asthma) at the time of enrolment. ${ }^{23}$ Inactive asthma was defined as no asthma symptoms, normal pulmonary function test, no asthma medications intake (both control and relief medications), no unscheduled clinic visits for asthma, no Emergency Department visit for asthma and no hospitalisation for asthma for 3 years. We determined asthma severity on the basis of the data obtained from the survey questionnaire (e.g., asthma symptoms) and medical record review (e.g., asthma medication and health-care utilisations). Study abstractor and physicians were blinded to patients' HOUSES.

Predictor (independent) variables

The primary predictor variables were HOUSES and other SES measures.

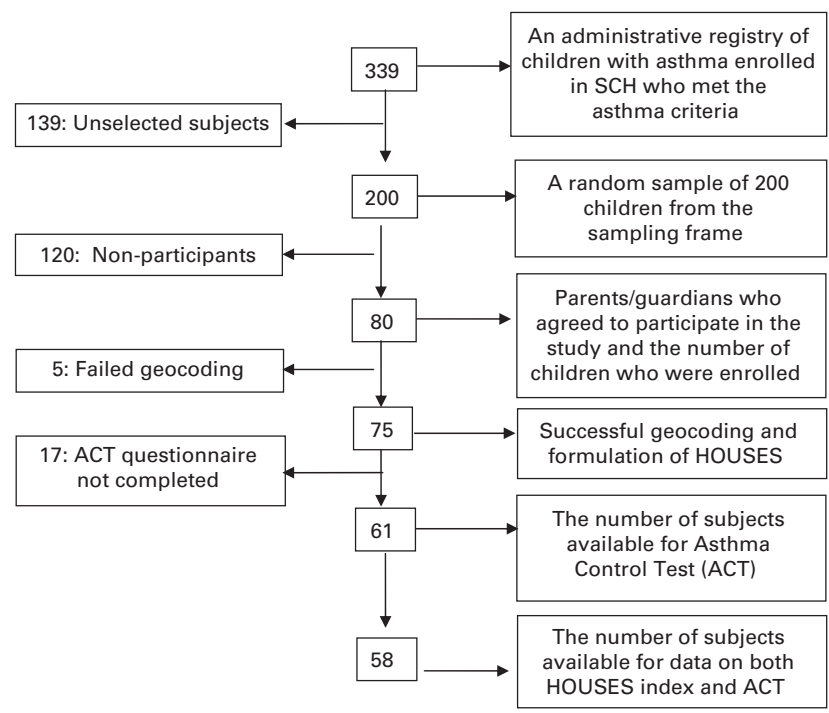

Figure 1. Diagram for subject enrolment.
HOUSES. The details of development and validation of HOUSES have been previously reported. ${ }^{11-13}$ Briefly, subjects' address information was geo-coded and matched to real property data obtained from the Assessor's Office of Sioux Falls (Minnehaha and Lincoln counties), South Dakota. HOUSES was originally developed on the basis of seven components of property data (homestead code, lot size of housing unit, housing unit size, number of bedrooms and bathrooms, and estimated taxable property value) and six neighbourhood characteristics (per cent of householders that are female, per cent of householders that are non-family householders, per cent of householders speaking English as a second language, per cent born in foreign countries, per cent in population with less than high school education and per cent of population with family income below the poverty level). ${ }^{12}$ These factors were then pared down to four variables (number of bedrooms, number of bathrooms, housing unit square footage and taxable property value) after factor analysis. These four factors were formulated into a single $z$-score assigned to each individual patient and categorised into tertiles. ${ }^{12}$ Parents/caregivers were blinded to their SES as measured by HOUSES.

Other SES measures. Other individual-level SES measures in this study included parental education levels, family income, Hollingshead index $(\mathrm{HI})^{24,25}$ and Nakao-Treas index (NKI). ${ }^{26}$ Parental educational level was ascertained by asking what the highest level of education attained by a parent or primary caregiver was. This was reported as three categories (high school graduate or below, some college education, and college degree or graduate or professional degree) for analysis. Family income was categorised into three groups $(<\$ 49,999, \$ 50,000-139,999$ and $>\$ 140,000)$ for analysis. The $\mathrm{HI}$ was based on four factors: parental education, parental occupation, sex and marital status to develop a family's composite SES. ${ }^{25} \mathrm{HI}$ scores range from 8 to 66 with higher numbers reflecting higher SES and categorised into tertiles. The NKI was derived from measures of education, occupation and income. ${ }^{26} \mathrm{NKI}$ scores range from 0 to 100 with lower numbers reflecting more prestigious occupation and categorised into tertiles.

Other variables pertaining to baseline characteristics of subjects In addition to sociodemographic variables, we collected pertinent variables to study the general health status of children, quality of life of parents, smoking exposure at home, overweight status of children and other atopic conditions.

General health status of study subjects was assessed by a five-point Likert Scale based on caregiver's self-report to the question, 'In general, how would you describe your child's overall health now?' Optional answers were ' 1 ' indicating poor health to ' 5 ' indicating excellent health at the time

Box 1 Asthma criteria ${ }^{15}$

Asthma was defined if a physician (a pulmonologist) had made a diagnosis of asthma and the presence of two or more of the following three conditions:

1. History of cough with dyspnoea and/or wheezing, OR history of cough and/or dyspnoea plus wheezing on exam,

2. Substantial variability in symptoms from time to time or periods of weeks or more when symptoms were absent and

3. Two or more of the following:

Sleep disturbance by nocturnal cough and wheeze

Non-smoker (14 years or older)

Nasal polyps

Blood eosinophilia higher than 300/ $\mu$ l

Positive wheal and flare skin tests OR elevated serum lgE History of hay fever or infantile eczema OR cough, dyspnoea and wheezing regularly on exposure to an antigen Pulmonary function tests showing one $\mathrm{FEV}_{1}$ or $\mathrm{FVC}<70 \%$ predicted and another with at least $20 \%$ improvement to an $\mathrm{FEV}_{1}$ of higher than $70 \%$ predicted OR methacholine challenge test showing $\geqslant 20 \%$ decline in $\mathrm{FEV}_{1}$ Favourable clinical response to bronchodilator 
of enrolment. We adopted this question from the 2002 National Health Interview Survey questions, which was used in our earlier studies. ${ }^{11,12}$

Quality of life of caregivers of children with asthma was assessed by the validated 'Linear Analog Self-Assessment Quality of Life' questionnaire. ${ }^{27}$ The single-item survey question was 'On a scale from 0 to 10 , with 0 being your quality of life is as bad as it could be and 10 being your quality of life is as good as it could be, how would you rate your overall quality of life during the past week, including today?'

Smoking exposure in the child's household: smoking exposure at home was assessed in relation to SES measures as this is an important variable for asthma control status. The response was categorised into a binary variable based on the response to 'Does anyone in the child's household use cigarettes, cigars or pipe tobacco?'

We determined overweight status $(\geqslant 95 \%$ of body mass index for age and gender) of children based on parents' estimated weight and height at the time of the study. Atopic conditions (a physician's diagnosis of atopic dermatitis or eczema and allergic rhinitis or hay fever) were obtained from parents through the administered questionnaire.

\section{Data analysis}

The primary aims of the analysis were to determine the association of HOUSES with risk of uncontrolled asthma. On the basis of $t$-test for testing statistical significance, we had $\sim 80 \%$ power to detect an effect size of $1.1 \mathrm{~s}$. d. differences in HOUSES between children with controlled asthma and those with uncontrolled asthma. We summarised baseline characteristics of children with controlled asthma and those with uncontrolled asthma using descriptive statistics. Correlation among SES measures such as family income, parental educational levels, $\mathrm{HI}$ and NKI was evaluated using Pearson's correlation coefficients or unweighted Cohen's Kappas. HOUSES was natural-log transformed to address its non-Gaussian distribution and categorised into tertiles for categorical analysis for HOUSES. To calculate odds ratios (ORs) and corresponding 95\% confidence interval (CI) for associations between SES measures and odds of uncontrolled asthma, data were initially fit to univariate logistic regression models. Data were fit to multivariate logistic regressions to model associations between HOUSES in continuous and categorical variables and risk of uncontrolled asthma by adjusting pertinent confounders. We chose these pertinent variables for adjustment on the basis of univariate analysis results in Table 1 using the Greenland's entry criteria for statistical modelling $(P<0.2)$. The association between other SES measures and asthma control status was determined in a similar fashion. To assess asthma severity as a secondary outcome of this study, we applied similar analyses.

Statistical significance was tested using two-sided alpha $=0.05$. All missing data were reported in the results. All analyses were based on $a$ priori hypothesis. All analyses were done using STATA (Version 12; StataCorp, College Station, TX, USA).

\section{RESULTS}

\section{Subject demographics}

Eighty of the 200 asthmatic children and their parents invited agreed to participate in this study (40\%). Comparison of characteristics of study subjects are summarised in Table 1. Approximately half (54\%) were male. Almost all (98\%) were Caucasian, reflecting the surrounding population (91\%). The proportions of parents who had high school education or below, some college education, or college education or above were $34 \%$ $(n=27), 35 \%(n=28)$ and $31 \%(n=25)$, respectively. All study subjects met the criteria for definite asthma mentioned in Table 1. The mean of log-transformed HOUSES were 2.26 (s.d.: 0.59). The mean age of subjects was 9.6 (s.d.: 3.1) years. The prevalence of poorly controlled asthma by ACT and persistent asthma by NAEPP guidelines were 13 and 23\%, respectively. Among children whose asthma severity was available $(n=74), 56$ had mild intermittent, 1 had inactive asthma, 12 had mild persistent, 4 had moderate persistent asthma and 1 had severe asthma. Of the 80 subjects, 18 children (23\%) were exposed to cigarette smoke in the home.

Availability of HOUSES and correlation with other SES measures We successfully geo-coded and matched addresses with property data for 75 of 80 subjects (94\%) at the time of enrolment. HOUSES
Table 1. Characteristics of children with asthma with controlled asthma and those with uncontrolled asthma by ACT

\begin{tabular}{|c|c|c|c|}
\hline & $\begin{array}{l}\text { Children with } \\
\text { controlled } \\
\text { asthma } \\
(A C T \geqslant 20) \\
(\mathrm{n}=53)\end{array}$ & $\begin{array}{l}\text { Children with } \\
\text { uncontrolled } \\
\text { asthma } \\
(A C T \leqslant 19) \\
(\mathrm{n}=8)\end{array}$ & P-value \\
\hline Gender (male) & 27 (51\%) & $4(50 \%)$ & 0.96 \\
\hline Age (years), mean (s.d.) & $9.81(3.19)$ & $8.75(1.16)$ & 0.36 \\
\hline \multicolumn{4}{|l|}{ Ethnicity } \\
\hline White & $52(98 \%)$ & $7(88 \%)$ & 0.12 \\
\hline Non-white & $1(2 \%)$ & $1(12 \%$ & \\
\hline \multicolumn{4}{|l|}{ Smoking exposure at home } \\
\hline Yes & $8(15 \%)$ & $2(25 \%)$ & 0.48 \\
\hline No & $45(85 \%)$ & $6(75 \%)$ & \\
\hline \multicolumn{4}{|l|}{ Overweight $(\mathrm{n}=77)^{\mathrm{a}}$} \\
\hline Yes & $6(13 \%)$ & $2(20 \%)$ & 0.53 \\
\hline No & 42 (87\%) & $8(80 \%)$ & \\
\hline \multicolumn{4}{|l|}{ Other atopic conditions } \\
\hline Yes & 35 (66\%) & $4(50 \%)$ & 0.38 \\
\hline No & $18(34 \%)$ & $4(50 \%)$ & \\
\hline \multicolumn{4}{|l|}{ Asthma severity $(\mathrm{n}=74)^{\mathrm{a}}$} \\
\hline Persistent asthma & $8(16 \%)$ & $5(63 \%)$ & 0.004 \\
\hline Intermittent asthma & 41 (84\%) & $3(37 \%)$ & \\
\hline $\begin{array}{l}\text { Quality of life of parents, } \\
\text { mean (s.d.) }\end{array}$ & $8.79(1.23)$ & $7.38(1.85)$ & 0.006 \\
\hline $\begin{array}{l}\text { General health status of } \\
\text { child, mean (s.d.) }\end{array}$ & $1.91(0.77)$ & $3.25(0.71)$ & $<0.001$ \\
\hline HOUSES, mean (s.d.) $(n=75)$ & $2.29(0.56)$ & $1.78(0.38)$ & 0.016 \\
\hline HI, mean (s.d.) $(n=74)$ & $50.76(12.53)$ & $50.57(9.62)$ & 0.97 \\
\hline NKI, mean (s.d.) $(n=74)$ & $57.32(14.07)$ & $54.57(15.64)$ & 0.63 \\
\hline \multicolumn{4}{|l|}{ Parents education } \\
\hline Some college or less & $16(30 \%)$ & $2(25 \%)$ & 0.67 \\
\hline College graduate & $18(34 \%)$ & $4(50 \%)$ & \\
\hline Graduate school & $19(36 \%)$ & $2(25 \%)$ & \\
\hline \multicolumn{4}{|l|}{ Income in three groups $(\mathrm{n}=74)^{\mathrm{a}}$} \\
\hline$<\$ 50,000$ & $6(13 \%)$ & $5(63 \%)$ & 0.005 \\
\hline$\$ 50,000-140,000$ & 27 (57\%) & $2(25 \%)$ & \\
\hline$>\$ 140,000$ & $14(30 \%)$ & $1(12 \%)$ & \\
\hline
\end{tabular}

The variables that were not available for all 80 subjects are indicated by showing the number of subjects with available data.

Abbreviations: ACT, Asthma Control Test; HI, Hollingshead index; HOUSES, housing-based socioeconomic index; NKI, Nakao-Treas index.

${ }^{a}$ For these variables in the table, the number of subjects do not add up to 61 because some subjects did not have both ACT score and these variables.

had moderate-good correlation with parental income $(k=0.46$, $P<0.001), \mathrm{HI}(r=0.36, P=0.002)$ and NKI $(r=0.40, P<0.001)$, and the results are summarised in Supplementary Figures 1 and 2 . HOUSES had poor agreement with parent education levels (weighted $k=0.14, P=0.043$ ).

Association between HOUSES and other SES measures and asthma control

Of the 80 subjects, 61 had parents who completed ACT but 3 of 61 subjects did not have HOUSES index leaving 58 subjects for the analysis for the association between HOUSES and asthma control. Six of the 19 subjects from the lowest HOUSES stratum (SES) (31.6\%), 1 out of 21 subjects from the intermediate HOUSES 
stratum (4.8\%) and 1 out of 18 subjects from the highest HOUSES stratum $(5.6 \%)$ had poorly controlled asthma by ACT $(P=0.023)$. In univariate analyses, HOUSES as a continuous variable was inversely associated with risk of poorly controlled asthma $(\mathrm{OR}=$ 0.21 per increment of 1 unit increase of log-transformed HOUSES, $95 \% \mathrm{Cl}, 0.049-0.89, P=0.04)$. As smoking exposure and overweight status were associated with risk of uncontrolled asthma, we adjusted the association between HOUSES and risk of uncontrolled asthma. The results in multivariate models are summarised in Table 2, which showed an inverse association of HOUSES with risk of uncontrolled asthma regardless of HOUSES use with categorical or continuous variables.

Parents' income was inversely associated with risk of uncontrolled asthma and this was true in a multivariate model adjusting for smoking exposure and overweight status as shown in Table 2. Other SES measures including parental educational levels, $\mathrm{HI}$, and NKI were not associated with risk of uncontrolled asthma (data not shown).

Association between HOUSES and other asthma outcomes Asthma severity as a secondary outcome was available for 74 subjects. In our univariate analysis, children with intermittent asthma had higher log-transformed HOUSES than those with persistent asthma (mean \pm s.d.: $2.34 \pm 0.53$ vs. $2.00 \pm 0.76$, $P=0.048)$. HOUSES as a continuous variable was inversely associated with risk of uncontrolled asthma but approached statistical significance $(\mathrm{OR}=0.36$ per increment of 1 unit increase of log-transformed HOUSES, 95\% Cl: 0.12-1.04, $P=0.060$ ). However, HOUSES measured in tertiles was not associated with risk of persistent asthma. For family income in tertiles, compared with the lowest income group, the intermediate $(\mathrm{OR}=0.1695 \% \mathrm{Cl}$, $0.04-0.63, P=0.01)$ and the highest income $(\mathrm{OR}=0.07,95 \% \mathrm{Cl}$, $0.01-0.63, P=0.02$ ) strata had lower odds of poorly controlled asthma in our univariate analyses. Parental educational levels, $\mathrm{HI}$ and NKI were not associated with asthma severity (data not shown).

Table 2. A multivariate logistic regression model for the association between HOUSES and risk of uncontrolled asthma

\begin{tabular}{|c|c|c|}
\hline & \multicolumn{2}{|c|}{ Risk of uncontrolled asthma } \\
\hline & Adjusted OR $(95 \% \mathrm{Cl})$ & P-value \\
\hline \multicolumn{3}{|c|}{ Model 1 based on HOUSES in continuous variable } \\
\hline HOUSES in continuous variable $\mathrm{a}^{\mathrm{a}}$ & $0.21(0.05-0.92)$ & 0.04 \\
\hline Smoking exposure at home & $1.58(0.25-9.92)$ & 0.62 \\
\hline Overweight & $1.37(0.21-9.08)$ & 0.74 \\
\hline \multicolumn{3}{|l|}{ Model 2 based on HOUSES ${ }^{\mathrm{a}}$ in tertiles } \\
\hline \multicolumn{3}{|l|}{ HOUSES in tertiles } \\
\hline 1st tertile (lowest SES) & (ref) & \\
\hline 2nd tertile & $0.10(0.01-1.0)$ & 0.04 \\
\hline 3rd tertile (highest SES) & $0.13(0.01-1.31)$ & 0.09 \\
\hline Smoking exposure at home & $1.45(0.21-10.37)$ & 0.71 \\
\hline Overweight & $1.10(0.16-7.71)$ & 0.92 \\
\hline \multicolumn{3}{|l|}{ Model 3 based on income in tertiles } \\
\hline \multicolumn{3}{|l|}{ Income in tertiles } \\
\hline 1st tertile (lowest SES) & (ref) & \\
\hline 2nd tertile & $0.07(0.01-0.50)$ & 0.01 \\
\hline 3rd tertile (highest SES) & $0.08(0.01-0.92)$ & 0.04 \\
\hline Smoking exposure at home & $1.87(0.23-15.03)$ & 0.56 \\
\hline Overweight & $1.84(0.24-14.27)$ & 0.56 \\
\hline \multicolumn{3}{|c|}{$\begin{array}{l}\text { Abbreviations: Cl, confidence interval; HOUSES, housing-based socio- } \\
\text { economic index; OR, odds ratio; ref, referent; SES, socioeconomic status. } \\
\text { 'Log-transformed HOUSES index. }\end{array}$} \\
\hline
\end{tabular}

Although not necessarily asthma-related outcomes, higher SES as measured by HOUSES was associated with a lower risk of exposure to smoking at home, better general health status of children and higher quality of life of parents/caregivers (data not shown).

\section{DISCUSSION}

Main findings

In this exploratory study, we successfully geo-coded and obtained HOUSES indices for $94 \%$ of the study subjects in a setting outside the original counties in which the index had been developed and validated. Multivariate models showed that HOUSES was independently associated with the risk of uncontrolled asthma (Table 2). Only family income (as another SES measure) was inversely correlated with risks of both uncontrolled asthma and persistent asthma but other SES measures were not correlated with either of asthma outcomes. HOUSES had moderate correlations with other SES measures except parental educational levels suggesting little redundancy in measuring one's SES by HOUSES and other SES measures.

\section{Strengths and limitations of this study}

The main strength of this study was asthma ascertainment of study subjects by the predetermined criteria for asthma and paediatric pulmonologists' diagnoses. Another strength was the availability of standardised and validated measures of asthma control status and asthma severity. This may minimise the subjectivity of asthma ascertainment and asthma outcome measures that often are a limitation in studies of other chronic conditions.

In addition, determination of HOUSES was independent of asthma outcome measures as study abstractor and physicians were blinded to patients' HOUSES. An advantage of HOUSES is that it requires only ascertaining the subject's address, which precludes common inaccuracies that may arise with other measures of SES. Another strength of this study was the comparison of four different measures of SES with HOUSES.

Our study has limitations. This study applied HOUSES to both a new region (Sioux Falls, SD, USA) and a new outcome (asthma control status) at the same time and, thus, it might make it difficult to interpret. However, SES as a predictor for asthma control status has been well established ${ }^{28-30}$ and this provided a conceptual basis for this present study. Also, associations of HOUSES with smoking exposure and general health status were similar to those observed in our previous studies. ${ }^{11,12}$ This provides support for the external validity of the HOUSES index. The study setting was predominantly Caucasian (98\%) and it is unclear whether this study would be generalisable to a setting with more ethnic diversity.

It is reassuring to note, however, that HOUSES has previously been developed and validated in Jackson County, Missouri (Kansas City, MO, USA), which is a more diverse and larger urban population than either Sioux Falls, South Dakota, or Olmsted County, Minnesota. ${ }^{11,12}$ Also, utilisation of HOUSES is limited by the variability of publicly accessible housing data. There is variation by county in how data are stored, how easily the data can be retrieved and the completeness of data. However, availability of real property data is assured in most counties as they are a basis for real property taxation.

An important limitation was the small sample size and incomplete data on ACT that limited statistical power to fully address the aims of this study. However, the main outcome of interest (asthma control) was powered appropriately to address the study aim. Although we attempted random sampling, study exclusion criteria and the low response rate did limit true random sampling. The study results need to be replicated in studies with larger sample sizes. Despite the availability and utility of HOUSES, 
another major limitation is the uncertainty of generalisability of HOUSES outside the United States. Future studies need to address this.

Interpretation of findings in relation to previously published work This exploratory study shows that HOUSES and family income were associated with asthma control status in a study setting different from those used in our previous HOUSES research. Study findings remain consistent with the literature on the association between SES and asthma control, ${ }^{28-30}$ and, generally, the findings here are consistent with those in our earlier studies. ${ }^{11,12}$

We did not address a pathway model of identifying mediating factors that account for associations between SES and differential health outcomes. ${ }^{31}$ The sample size in this study is too small to do this, but use of HOUSES in such studies could be very helpful. However, we did adjust results for associations of between HOUSES and risk of uncontrolled asthma with potential risk factors for uncontrolled asthma such as smoking exposure ${ }^{32,33}$ and overweight status. ${ }^{34}$ HOUSES as a continuous variable was associated with risk of persistent asthma, but the results could not be confirmed in the analysis based on HOUSES in tertiles. In this study, we found that HOUSES was associated with exposure to smoking at home, general health status of children and quality of life of parents/caregivers (data not shown). We also confirmed the previous observation that children with uncontrolled asthma had poor general health and quality of life of their parents. ${ }^{35}$ Family income was associated with uncontrolled asthma and persistent asthma, consistent with the literature. ${ }^{11,36}$ However, other SES measures were not associated with outcome measures of interest in our study. Given the moderate correlation among SES measures, income might better reflect one's SES in the context of asthma control than other SES measures.

Overall, despite the moderate correlation of HOUSES with other SES measures, the HOUSES index can be a useful measure of SES in asthma research in differing study settings. HOUSES has unique strengths for overcoming the absence of SES measures in commonly used data sets.

Implications for future research, policy and practice

In the United States, according to Healthy People 2020, one of the four overarching health goals is to 'achieve health equity, eliminate disparities, and improve the health of all groups'. ${ }^{37}$ This statement indicates the US government's major commitment to addressing disparities in health across race, ethnicity and SES. In this context, a few potential implications related to availability of the HOUSES index to research and practice can be explored. First, in research, large administrative data sets are increasingly being utilised for health disparities research. Thus, HOUSES will enable us to address research questions using large administrative data sets when SES is an independent or mediating variable. Second, in practice, clinicians and health care systems may better define needs of patients in treatment planning and altering health care services as SES measures are easily accessible. ${ }^{38}$ Finally, in public health, HOUSES enables surveillance of health disparities over time. Current literature also recognises that housing itself as physical and social space is critical to daily living and is a potential contributor to health disparities. ${ }^{39,40}$

\section{CONCLUSIONS}

HOUSES is a potentially useful individual-level measure of SES for researching childhood asthma outcomes. This study indicates that HOUSES is associated with asthma control status among children. Our study findings need to be replicated in larger studies.

\section{ACKNOWLEDGEMENTS}

The authors acknowledge support from the members of the Pediatric Asthma Epidemiology Research Unit and, in particular, Elizabeth Krusemark for her administrative support.

\section{CONTRIBUTIONS}

$\mathrm{MNH}$ was involved in the interpretations and analysis of the data and prepared the manuscript. MCL was involved in the conception and design of the study, collection of the data and critically revised the final manuscript. DMF, ARW, TJB, JAS, BPY and YJJ were involved in the conception and design of the study, interpretation and analysis of the data, and critically revised the final manuscript.

\section{COMPETING INTERESTS}

The authors declare no conflict of interest.

\section{FUNDING}

This work was supported by the Mayo-Sanford Research Initiative and a National Institutes of Health grant (R21 HD51902) from the National Institute of Child Health and Human Development.

\section{REFERENCES}

1 Juhn YJ, Sauver JS, Katusic S, Vargas D, Weaver A, Yunginger J. The influence of neighborhood environment on the incidence of childhood asthma: a multilevel approach. Soc Sci Med 2005; 60: 2453-2464.

2 Kanervisto M, Vasankari T, Laitinen T, Heliövaara M, Jousilahti P, Saarelainen S. Low socioeconomic status is associated with chronic obstructive airway diseases. Resp Med 2011; 105: 1140-1146.

3 Choi WJ, Um IY, Hong S, Yum HY, Kim H, Kwon H. Association between household income and asthma symptoms among elementary school children in Seoul. Environ Health Toxicol 2012; 27: e2012020.

4 Vila D, Rand CS, Cabana MD, Quinones A, Otero M, Gamache C et al. Disparities in asthma medication dispensing patterns: the case of pediatric asthma in Puerto Rico. J Asthma 2010; 47: 1136-1141.

5 Krieger N, Chen JT, Waterman PD, Rehkopf DH, Subramanian SV. Race/ethnicity, gender, and monitoring socioeconomic gradients in health: a comparison of areabased socioeconomic measures-the public health disparities geocoding project. Am J Public Health 2003; 93: 1655-1671.

6 Liberatos P, Link BG, Kelsey JL. The measurement of social class in epidemiology. Epidemiol Rev 1988; 10: 87-121.

7 Capili CR, Hettinger A, Rigelman-Hedberg N, Fink L, Boyce T, Lahr B et al. Increased risk of pertussis in patients with asthma. J Allergy Clin Immunol 2012; 129: 957-963.

8 Simon AE, Lukacs SL, Mendola P. Emergency department laboratory evaluations of fever without source in children aged 3 to 36 months. Pediatrics 2011; 128: e1368-e1375.

9 Lang DM, Polansky M, Sherman MS. Hospitalizations for asthma in an urban population: 1995-1999. Ann Allergy Asthma Immunol 2009; 103: 128-133.

10 Pardo-Crespo MR, Narla NP, Williams AR, Beebe TJ, Sloan J, Yawn BP et al. Comparison of individual-level versus area-level socioeconomic measures in assessing health outcomes of children in Olmsted County, Minnesota. J Epidemiol Community Health 2013; 67: 305-310.

11 Butterfield MC, Williams AR, Beebe T, Finnie D, Liu H, Liesinger J et al. A twocounty comparison of the HOUSES index on predicting self-rated health. J Epidemiol Community Health 2011; 65: 254-259.

12 Juhn YJ, Beebe TJ, Finnie DM, Sloan J, Wheeler PH, Yawn B et al. Development and initial testing of a new socioeconomic status measure based on housing data. J Urban Health 2011; 88: 933-944.

13 Johnson MD, Urm SH, Jung JA, Yun HD, Munitz GE, Tsigrelis C et al. Housing databased socioeconomic index and risk of invasive pneumococcal disease: an exploratory study. Epidemiol Infect 2012; 3: 1-8.

14 Center for Disease Control and Prevention, National Center for Health Statistics. 2002 National Health Interview Survey, http://www.cdc.gov/nchs/data/series/ sr_10/sr10_222.pdf, accessed 22 September 2004

15 Yunginger J, Reed CE, O'Connell EJ, Melton J, O'Fallon WM, Silverstein MD. A community-based study of the epidemiology of asthma: incidence rates, 1964-1983. Am Rev Respir Dis 1992; 146: 888-894. 
16 Beard M, Yunginger JW, Reed CE, O'Connell EJ, Silverstein MD. Interobserver variability in medical record review: an epidemiological study of asthma. J Clin Epidemiol 1992; 45: 1013-1020.

17 Juhn YJ. Influence of asthma epidemiology on the risk for other diseases. Allergy Asthma Immunol Res 2011; 4: 122-131.

18 Andrew HL, Robert SZ, Christine AS, Nancy KO, Bradley EC, Kathleen R et al. The Childhood Asthma Control Test: retrospective determination and clinical validation of a cut point to identify children with very poorly controlled asthma. J Allergy Clin Immunol 2010; 1262: 267-273, 273.e1.

19 National Heart Lung and Blood Institute, National Asthma Education and Prevention Program. Expert Panel Report 3(EPR3): Guidelines for the diagnosis and management of asthma. National Institutes of Health, US Department of Health and Human Services 2007, http://www.nhlbi.nih.gov/guidelines/asthma/asthgdln. pdf.

20 Nathan RA, Sorkness CA, Kosinski M, Schatz M, Li JT, Marcus P et al. Development of the Asthma Control Test: a survey for assessing asthma control. J Allergy Clin Immunol 2004; 113: 59-65.

21 Buchacz K, Armon C, Palella FJ, Baker RK, Tedaldi E et al. CD4 Cell Counts at HIV Diagnosis among HIV Outpatient Study Participants, 2000-2009. AIDS Res Treat 2012; 2012: 869841.

22 Lemanske RF Jr, Mauger DT, Sorkness CA, Jackson DJ, Boehmer SJ, Martinez FD et al. Step-up therapy for children with uncontrolled asthma while receiving inhaled corticosteroids. N Engl J Med 2010; 362: 975-985.

23 National Asthma Education and Prevention Program. Expert Panel Report 3 (EPR3): Guidelines for the Diagnosis and Management of Asthma-Summary Report 2007. J Allergy Clin Immunol 2007; 120: S94-S138.

24 Rieppi R, Greenhill LL, Ford RE, Chuang S, Wu M et al. Socieconomic status as a moderator of ADHD treatment outcomes. J Am Acad Child Adolesc Psychiatry 2002, 41: 269-277.

25 Hollingshead A. Four Factor Index of Social Status. Department of Psychology, Yale University: New Haven, CT, USA, 1975.

26 Nakao K, Treas J. The 1989 socioeconomic index of occupations: construction from the 1989 Occupational Prestige Scores. General Social Survey Methodological Report No. 74 University of Chicago, National Opinion Research Center: Chicago, IL, USA, 1992.

27 Heimbeck I, Wjst M, Apfelbacher CJ. Low vitamin D serum level is inversely associated with eczema in children and adolescents in Germany. Allergy 2013; 68 906-910.

28 Bloomberg GR, Banister C, Sterkel R, Epstein J, Bruns J, Swerczek L et al. Socioeconomic, family, and pediatric practice factors that affect level of asthma control. Pediatrics 2009; 123: 829-835

29 Ungar WJ, Paterson JM, Gomes T, Bikangaga P, Gold M, To T et al. Relationship of asthma management, socioeconomic status, and medication insurance characteristics to exacerbation frequency in children with asthma. Ann Allergy Asthma Immunol 2011; 106: 17-23.

30 Su K-C, Tsai C-C, Kuo L-C, Kuo S-H, Perng D-W. Budesonide/formoterol combination as a maintenance and rescue therapy. J Asthma 2009; 46: 647-651.

31 Diez Roux AV. Conceptual approaches to the study of health disparities. Annu Rev Public Health 2011; 13: 1-18.

32 Tinuoye O, Pell JP, Mackay DF. Meta-analysis of the association between secondhand smoke exposure and physician-diagnosed childhood asthma. Nicotine Tob Res 2013; 15: 1475-1483.

33 Mannino DM, Moorman JE, Kingsley B, Rose D, Repace J. Health effects related to environmental tobacco smoke exposure in children in the United States: data from the Third National Health and Nutrition Examination Survey. Arch Pediatr Adolesc Med 2001; 155: 36-41.

34 Quinto KB, Zuraw BL, Poon K-YT, Chen W, Schatz M, Christiansen SC. The association of obesity and asthma severity and control in children. J Allergy Clin Immunol 2011; 128: 964-969.

35 Halterman JS, Yoos HL, Conn KM, Callahan PM, Montes G, Neely TL et al. The impact of childhood asthma on parental quality of life. J Asthma 2004; 41 645-653.

36 Hajat A, Kaufman JS, Rose KM, Siddiqi A, Thomas JC. Long-term effects of wealth on mortality and self-rated health status. Am J Epidemiol 2011; 173. $192-200$.

37 The US Department of Health and Human Services. Healthy People 2020. Washington, DC, USA, 2011.

38 Chen E, Strunk RC, Trethewey A, Schreier HMC, Maharaj N, Miller GE. Resilience in low-socioeconomic-status children with asthma: adaptations to stress. J Allergy Clin Immunol 2011; 128: 970-976.

39 Tsemberis S, Kent D, Respress C. Housing stability and recovery among chronically homeless persons with co-occuring disorders in Washington, DC. Am J Public Health 2011; 102: 13-16.

40 Cutts DB, Meyers AF, Black MM, Casey PH, Chilton M, Cook JT et al. US housing insecurity and the health of very young children. Am J Public Health 2011, 101: 1508-1514.

(2) This work is licensed under a Creative Commons Attributioncc) NonCommercial-ShareAlike 4.0 International License. The images or other third party material in this article are included in the article's Creative Commons license, unless indicated otherwise in the credit line; if the material is not included under the Creative Commons license, users will need to obtain permission from the license holder to reproduce the material. To view a copy of this license, visit http:// creativecommons.org/licenses/by-nc-sa/4.0/

Supplemental Information accompanies the paper on the npj Primary Care Respiratory Medicine website (http://www.nature.com/npjpcrm) 